\title{
CARACTERÍSTICAS DEL DESPLAZAMIENTO FORZADO EN COLOMBIA*
}

Henry Fernández Pintol

Jimmy Sánchez Reyes ${ }^{2}$

\section{Resumen}

El presente estudio es una contribución a la explicación y comprensión de la problemática del desplazamiento forzado interno en Colombia, fenómeno considerado como violación masiva y múltiple de los derechos humanos, circunstancia de lesa humanidad además de ser infracción grave del Derecho Internacional Humanitario.

Se identificaron los antecedentes históricos, la dinámica regional del fenómeno, la existencia de factores estructurales asociados a las regiones expulsoras de la población y las serias contrariedades en la política pública entre otros. Se demuestra entonces la necesidad de focalizar la efectividad de la política pública con un enfoque estructural, regional, integral, diferencial y de derechos.

\section{Palabras clave}

Desplazado interno, Derechos Humanos, problemas estructurales.

\begin{abstract}
This study is a contribution to the explanation and understanding of the problem of internal displacement in Colombia; phenomenon considered as mass and multiple violation of the human rights, a situation against humanity as well as being a serious violation of international humanitarian law.

We identified the historical, regional dynamics of the phenomenon, the existence of structural factors related to the regions that expel population, and serious setbacks in public policy among others. It then demonstrates the need to focus the effectiveness of public policy with a structural approach, regional, integral, differential and rights.
\end{abstract}

\section{Keywords}

Internally Displaced, Human Rights, structural problems

* $\quad$ Parte de este artículo fue tomado del trabajo de grado del master de la Universidad de Cantabria dirigido por la Dra. María Hierro

1 Máster Iberoamericano en Cooperación Internacional y Desarrollo, Universidad de Cantabria.

2 Especialista en Gerencia de proyectos, Universidad del Tolima. Director General Corporación Proyectos de Paz (PROYPAZ). 


\title{
Introducción
}

\begin{abstract}
"Ser desplazado es no entender nunca por qué te hicieron huir de los fuegos encontrados de bandas a las que jamás llamaste, de gentes que vinieron a sacarte de lo tuyo, de un Estado que no respondió al pacto fundamental de defenderte la vida, los bienes y la honra. Es pasar de la arboleda a los cráteres urbanos, es habitar en las dunas de polvo gris extendidas hasta el horizonte de los barrios marginales de nuestras selvas de cemento, mal llamadas ciudades." (Conferencia Episcopal de Colombia, 2005)
\end{abstract}

El presente estudio surge como una iniciativa particular de investigar fenómenos sociales del desarrollo, procura indagar sobre una de las problemáticas más graves de Colombia durante las últimas dos décadas: el fenómeno del desplazamiento forzado como consecuencia del conflicto armado interno. Esta investigación es exploratoria y descriptiva, cuyo objetivo central es explicar la situación general del desplazamiento forzado y sus múltiples dimensiones, mediante la revisión de datos estadísticos disponibles y estudios previos sobre el tema. Se identifican los antecedentes histórico-estructurales que condicionaron las raíces del problema, así como la dinámica regional y el papel de la política pública en materia de reparación integral de las víctimas del desplazamiento y la superación del estado de crisis humanitaria.

La relevancia de este tema radica en su caracterización, dado que el desplazamiento forzado de personas es considerado una violación a los derechos humanos y un problema de lesa humanidad. El caso colombiano ha sido catalogado como una violación masiva y múltiple de los derechos humanos y una infracción grave del Derecho Internacional Humanitario con graves costos sociales y humanos. A nivel mundial Colombia es el segundo país con mayor número de desplazamientos forzados internos, según estadísticas no oficiales desde mediados de los años ochenta hasta la fecha se han desplazado 4.629 .190 personas de su lugar de residencia habitual para salvar su integridad física.

Para la elaboración de este trabajo, se ha recurrido a diferentes fuentes de datos en su mayor parte fuentes secundarias, las estadísticas corresponden a tres centros, el primero de ellos de carácter oficial La Agencia Presidencial para la Acción Social y la Cooperación Internacional de Colombia (Acción Social) dos no gubernamentales (CODHES) Consultoría de Derechos Humanos para Desplazados y el Internal Displacement monitoring Center. Así como Naciones Unidas (N.U), el Banco Mundial, el PNUD y otras mencionadas en la bibliografía.

El ensayo se ha estructurado en cuatro apartados, el primero realiza la identificación del problema así como algunas definiciones conceptuales, el segundo, explora los antecedentes histórico-estructurales de la génesis del mismo, el tercer 
apartado aborda la dinámica regional y la configuración territorial así como el perfil socio-demográfico del desplazamiento, el cuarto revisa el papel de la política pública en materia de reparación y atención a las víctimas. Finalmente se exponen las conclusiones del trabajo.

\section{Identificación y definición del fenómeno del desplazamiento forzado interno}

Colombia enfrenta uno de los problemas sociales y humanitarios más graves a nivel mundial, el fenómeno del desplazamiento forzado como resultado del conflicto armado interno el cual ha generado un proceso masivo de migración forzada de personas de su lugar de residencia habitual para salvar su integridad física. Según estadísticas oficiales desde mediados de los años noventa hasta diciembre de 2009 se han desplazado 750.881 hogares equivalentes a 3.303.979 personas en condición de desplazamiento (Acción Social Colombia, 2009). ${ }^{3}$

Por otra parte, las estadísticas no oficiales construidas a partir de organizaciones no gubernamentales y de la sociedad civil representada en (CODHES, 2009) sustentan dentro de su base estadística, que desde 1985 hasta diciembre de 2008 se ha generado desplazamiento forzado a 925.838 familias para un total de 4.629.190 personas aproximadamente.

En términos socio demográficos se puede inferir que este tipo de desplazamiento por violencia es un grave problema nacional dado que representa el $7.2 \%{ }^{4}$ de la población, por tanto, siete de cada cien colombianos fue coaccionado a migrar por razones violentas en los últimos 20 años. Según la Organización Internacional para las Migraciones (OIM, 2009) y el centro de monitoreo para los desplazados internos (IDMC, 2010) tres países tienen el más grande y preocupante problema de desplazamiento: Sudán, Colombia e Iraq que juntos suman el $45 \%$ de toda la población desplazada del mundo.

A nivel mundial Colombia es el segundo país con mayor número de desplazados internos después de Sudán (4.900.000 personas) en tercer lugar está Iraq (2.840.000) después de la invasión, sin embargo, la mayor parte de la problemática se centra en el continente Africano (11,6 millones) donde se encuentra un gran volumen de desplazados en Somalia (1.300.000) R.D. Congo (1.400.000) y otros de la región (Internal Displacement monitoring Center IDMC, 2010). Ver Gráfico 1.

3 Fuentes estadísticas oficiales de la Agencia Presidencial para la Acción Social y la Cooperación Internacional de Colombia. De años anteriores a 1997 no se posee registros oficiales al respecto.

$4 \quad$ Número de personas desplazadas /total de la población del país. 
Gráfico 1. Países con más desplazados internos acumulados hasta 2008

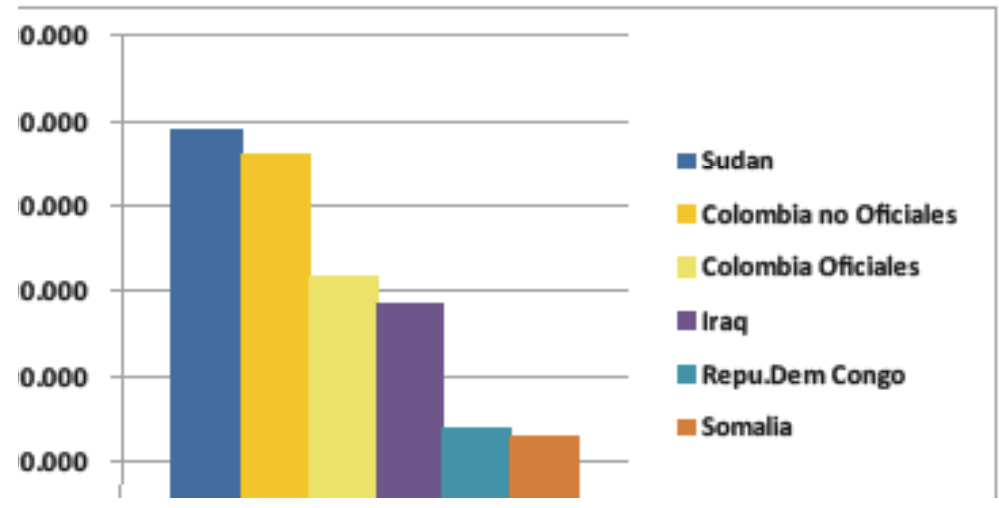

Fuente: Elaboración Propia con base en datos Acción Social Colombia, CODHES, e IDMC

\subsection{Conceptos}

El concepto de "desplazado interno" difiere ostensiblemente de los términos emigrante e inmigrante, así como de asilado y refugiado, en primer lugar, las denominaciones emigrar o inmigrar están asociadas convencionalmente a la libre voluntad, y capacidad subjetiva de los individuos de escoger moverse de un territorio o país sin coacción alguna (OIM, 2005); en segundo lugar, es necesario mencionar que el término desplazado interno será entendido como aparece en los principios rectores sobre desplazamiento forzado del reporte de las Naciones Unidas y se define como:

"persons or groups of persons who have been forced or obliged to flee or to leave their homes or places of habitual residence, in particular as a result of or in order to avoid the effects of armed conflict, situations of generalized violence, violations of human rights or natural or human-made disasters, and who have not crossed an internationally recognized state border" (Guiding Principles on Internal Displacement, 2004) $)^{5}$

La legislación colombiana acorde a los principios rectores de la ONU en el artículo 1 de la ley 387 de 1997 define:

5 United Nations Office For The Coordination Of Humanitarian Affairs 
"desplazada es toda persona que se ha visto forzada a emigrar dentro del territorio nacional abandonando su localidad de residencia o actividades económicas habituales, porque su vida, su integridad física, su seguridad o libertad personal han sido vulneradas o se encuentran directamente amenazadas, en cualquiera de las siguientes situaciones: conflicto armado interno, disturbios y tensiones interiores, violencia generalizada, violaciones masivas de los Derechos Humanos, infracciones al Derecho Internacional Humanitario $\mathrm{u}$ otras circunstancias emanadas de las situaciones anteriores que puedan alterar o alteren drásticamente el orden público."

Por su parte, el concepto de refugiado difiere del de desplazado interno únicamente por el cruce de fronteras entre Estados, dado que un refugiado es una persona que decide salir del país hacia otro para salvar su vida de situaciones adversas a su integridad; las Naciones Unidas lo define como una persona que:

"debido a fundados temores de ser perseguida por motivos de raza, religión, nacionalidad, pertenencia a determinado grupo social u opiniones políticas, se encuentre fuera del país de su nacionalidad y no pueda o, a causa de dichos temores, no quiera acogerse a la protección de tal país, o, a causa de dichos temores, no quiera regresar a él". (Convención sobre estatuto de los refugiados Naciones Unidas, 1951a 1967b)

Un asilado político según Acosta (2005) es la protección que un Estado otorga en su propio territorio a un nacional de otro Estado perseguido por razones políticas o ideológicas por las autoridades de otro Estado. Como se puede observar pareciera que los conceptos de refugiado y asilado fuesen lo mismo, sin embargo, como expone Camps (2005) son dos figuras que tienen en común el hecho de ser perseguidas individualmente, sin embargo, el régimen jurídico aplicable a uno y otro es diferente. El asilo político estará siempre sujeto a la soberanía y legislación del Estado que otorga el asilo, el refugiado estará amparado por la convención de Ginebra de 1951 modificada en 1967 como parte de los compromisos en materia humanitaria y de DDHH de todos los Estados amparada por las Naciones Unidas.

En este sentido, la presente investigación se delimitará al análisis del desplazamiento forzado interno resultado de elementos de coacción y amenaza de la población y no al flujo de las migraciones ordinarias, tampoco se revisará la problemática de los asilados y refugiados a pesar de constituirse la mayor parte de esta población en estados iniciales en desplazados internos, dado que al salir de las fronteras del país pierden esta categoría.

El caso de análisis no constituye un problema coyuntural de tendencias migratorias, dado que en primer lugar no es un acto voluntario de los individuos y en segunda instancia no puede paliarse solamente con medidas de emergencia, asistencia humanitaria, políticas y programas de retorno o mediante ajustes del mercado globalizado; es, en efecto, un problema social y una violación masiva y múltiple de 
los derechos humanos y del Derecho Internacional Humanitario en el que subyacen conflictos sociales y estructurales no resueltos históricamente, contradicciones en la construcción del Estado y la nación y, por tanto, de política pública, como se verá en los siguientes apartados.

\section{Antecedentes}

En este tipo de estudios uno de los aspectos que genera mayor debate es el de los factores históricos y estructurales del desplazamiento forzado. La mayoría de investigaciones sobre la comprensión y análisis centran su argumentación en aspectos relacionados con las dinámicas de la violencia histórica, el crimen y el surgimiento y fortalecimiento de los actores armados legales e ilegales como el eje central del problema. Otros científicos sociales plantean una explicación más estructural al comprender el desplazamiento como una forma de exclusión social, relacionada con problemas de tierras, narcotráfico, intereses económicos detrás de la guerra y falta de atención por parte del Estado. Este capítulo aborda las dos propuestas explicativas del problema de análisis al considerarlas complementarias y no excluyentes.

\subsection{Históricos}

En contraposición a lo que ocurre en otros países donde el desplazamiento forzado está asociado en el ochenta por ciento de los casos a hechos y circunstancias de guerra específicos entre Estados en un momento de tiempo determinado; en Colombia, este fenómeno es una constante histórica, una realidad recurrente de la historia nacional. En este sentido algunos autores señalan que el desplazamiento hace parte de la memoria de las familias y poblaciones y se ha constituido en un eje vertebral de la conformación territorial del país (Naranjo, 2001).

En esta misma línea otros autores ubican este intermitente movimiento forzado de población desde los siglos XVI y XVII, cuando miles de indígenas marchan lejos de las zonas disputadas por los conquistadores y colonizadores, en busca de preservar su cultura. Posteriormente, en el siglo XIX la guerra de independencia de la corona española y las guerras civiles enfrentaron al débil Estado central con proyectos e iniciativas regionales, impulsaron grandes olas migratorias de desplazados, una de estas olas migratorias significativas se registró en 1898 (500.000 personas aprox.) bajo el marco de la guerra de los mil días (Tovar, Naranjo, Rojas, 2001).

A mediados del siglo XX la violencia bipartidista de los dos únicos partidos políticos (liberales y conservadores) posteriores a la guerra civil de los mil días, multiplicó las acciones violentas segmentadas que generaron desplazamientos de cerca de 400.000 familias campesinas, asesinato de 180.000 personas y el abandono de cerca de 400.000 parcelas aproximadamente (Tovar, Naranjo, CODHES). 
Dentro de los aspectos históricos es evidente que la violencia es la causa principal del desplazamiento, desde esta perspectiva se ubica al desplazamiento como parte de la estrategia de los actores armados con propósito de expansión y dominio territorial. La violencia política se distingue por

"constituir un medio de lucha político social con el fin de mantener, modificar, sustituir o destruir un modelo de Estado o de sociedad, o para reprimir a un grupo humano con identidad dentro de la sociedad esté o no organizada" (Banco datos derechos humanos).

Numerosos trabajos explican las raíces ideológicas y sociales del conflicto armado colombiano caracterizado por la existencia de una violencia e insurgencia crónica (Informe D.H., PNUD, 2003a, 2007b). Los analistas se remiten a los difíciles y convulsionados años cincuenta y sesenta cuando surgen las múltiples fuerzas guerrilleras en Latinoamérica, entre ellas las FARC y el ELN. El surgimiento de las FARC se explica como resultado del encuentro entre la guerrilla campesina y el partido comunista en 1964 como respuesta a la ausencia de programas agrarios de inclusión campesina. Por su parte, el ELN, surge en el mismo año como resultado de la decisión de estudiantes y dirigentes sindicales de recurrir a un proyecto político socialista para transformar la sociedad colombiana (Zuluaga, 2004)

En este sentido la violencia se constituye en el elemento central e histórico en los procesos de desplazamiento forzado y está asociada al crimen y al abuso del poder, es indiscutible que si un grupo de población sale de una zona en masa está determinado por las dinámicas bélicas. Por tanto, el conflicto afecta a la sociedad civil por medio de amenazas, ataques, acciones, militares, reclutamientos y toma de municipios que genera así el desplazamiento reactivo de la población (ante un evento concreto) o preventivo (para evitar los eventos violentos relacionados con el conflicto) (Ibáñez, 2004).

Por tanto, el desplazamiento forzado tiene estrecha relación con la intensificación del conflicto armado y las estrategias violatorias del derecho internacional humanitario, generadas por los actores armados; y este surge, principalmente, en los territorios donde se incrementan las acciones armadas que atentan contra la vida, la seguridad física y las libertades personales y civiles de la población.

\subsection{Estructurales}

El enfoque de analistas centrado en una explicación más amplia del desplazamiento afirma que en esencia son tres los elementos concretos de estructura que generan el fenómeno: un problema de distribución de la tierra, el narcotráfico y la exclusión social por parte del Estado, los cuales al no haberse solucionado social e históricamente se han traducido en un deterioro consecutivo de la violencia. 
En este sentido, el problema de la distribución de la tierra y el desplazamiento más que una consecuencia del conflicto armado o un efecto secundario del mismo, constituye una estrategia de guerra empleada por los actores armados para fortalecer su control territorial, apropiar predios agrícolas y desocupar territorios en donde existen recursos naturales valiosos. Como afirma Uribe (2000)

"Estrategia desarrollada en alianza o con financiación de grupos privados cuyos intereses estarían induciendo el desplazamiento".

Detrás de las acciones de grupos armados se esconden, entonces, intereses de ganaderos, narcotraficantes, capitalistas nacionales y extranjeros. De ahí la afirmación sugestiva de algunos analistas en el sentido de "no hay desplazados porque hay guerra, sino que hay guerra para que haya desplazados" (Uribe, 2000) Por tanto, desde esta perspectiva de análisis, el desplazamiento es una estrategia histórica efectiva para ocupar tierras por parte de grupos de interés (Mondragón, 1998). La geografía de la guerra interna muestra que los desplazamientos no sólo han tenido lugar en las zonas importantes a nivel militar (corredores, zonas de repliegue) sino que éstos se han concentrado esencialmente, en lugares con recursos estratégicos y dinámicas económicas importantes (Fajardo 2002). La apropiación violenta de la tierra implica despojar a la población de su principal medio de subsistencia.

Al respecto dos autores resumen la problemática de la tierra en el siguiente extracto (Cubidez, Domínguez, 1999)

"la violencia de fin de siglo, con sus migraciones forzadas hacia los grandes centros urbanos, esconde principalmente las expropiaciones de tierras agrícolas para tornarlas ganaderas, o el control territorial de las regiones productoras de coca o amapola con el objetivo de adueñarse de la producción, el "gramaje" o el tráfico".

Otro factor de estructura que afecta la desintegración social del país y ha propiciado procesos forzados de migración es el narcotráfico, dado que no sólo ha realizado procesos de expropiación a favor de la consolidación terrateniente, sino que ha transformado las relaciones de poder, políticas, culturales y de producción en función del mismo. Forjaron un auge del mercado de cultivos de uso ilícito, que conlleva mayores presiones a las comunidades campesinas, debido a la demanda de tierras generadas por la economía ilegal, así como para el cultivo y comercio de coca, amapola y marihuana.

Por tanto, en estas regiones se genera un aislamiento propicio para la instalación de redes de poder y de comercio de producción de uso ilícito, que genera rentabilidad para quienes procesan y comercian, que profundizan el empobrecimiento y el desplazamiento de la población que no tiene que ver con el negocio o si tienen lo hacen en la escala más baja de poder. Así mismo, algunas políticas y estrategias antidrogas implican fumigaciones y acciones militares que aumentan las olas migratorias y el abandono del territorio (Bello, Naranjo, Codhes, Tovar). 
El problema de la exclusión social constituye otro de los fenómenos de la geografía nacional, al respecto algunos autores definen al Estado colombiano como un estado incipiente y excluyente dado que no se ha constituido en principio de orden, no es soberano en toda la nación, no tiene el monopolio de las armas y los tributos; así mismo, no integra igualmente a las regiones, protege eventualmente los derechos de los ciudadanos y permite la existencia de órdenes y grupos alternativos de poder (Uribe,1998). Existen, entonces, unos territorios medianamente integrados y sujetos a la autoridad pública y el gasto social y otros al margen del mismo los cuales son territorios excluidos donde se dificulta el reconocimiento de derechos básicos y las condiciones mínimas de ciudadano de la nación (Naranjo, 2002).

Por tanto, los desplazados son históricamente grupos y regiones de personas excluidos en desventaja y si son incluidos es de forma perversa en las dinámicas de expropiación de sus tierras. Sus territorios ancestrales atraen las miradas de interés multinacionales y nacionales, que ven en sus tierras riquezas minerales o naturales geoestratégicas “estos grupos sociales hacen el tránsito de víctimas históricas de los procesos de exclusión a víctimas del destierro y el despojo" (Bello, 2004).

\section{Dinámica y perfil socio-demográfico del desplazamiento forzado}

En este apartado se analiza las dinámicas del desplazamiento forzado a lo largo de las dos últimas décadas, se comparan las cifras oficiales y las no oficiales construidas por las ONG, se presentan los comportamientos de tendencia y sus diferentes fases de reproducción. Igualmente se expondrán a través de mapas cartográficos las regiones que sufren el impacto de la salida de población, así como las zonas receptoras y los diferentes grupos perpetradores de agresión por territorios.

Igualmente se presenta el perfil sociodemográfico de las diferentes personas que por razones violentas dejan sus territorios, este muestra la realidad del desplazamiento a través de un enfoque diferencial que pone de manifiesto el tipo de comunidades étnicas, el sexo, la edad y las discapacidades, dado que este análisis estadístico permite diseñar estrategias de política acordes a las realidades del conflicto y no a través de generalidades.

\subsection{Dinámica del desplazamiento}

El fenómeno del desplazamiento forzado a lo largo de las dos últimas décadas ha presentado una tendencia variable pero creciente en términos generales, ver Gráfico 2, se observa según las estadísticas cómo presenta cuatro momentos de expansión exacerbada en los años de 1987 a 1989, de 1995 a 1997, de 1999 a 2002 y vuelve a incrementarse en 2007 y 2008, los analistas relacionan estos picos de migración forzada con incrementos sustanciales en los niveles de violencia, combates militares, fumigaciones y acciones de la fuerza pública (Acción Social, CODHES 2009). 
Desafortunadamente en los años 2007, 2008 y 2009 según cifras no oficiales se observa un crecimiento del desplazamiento comparable con los de los años $2001 \mathrm{y}$ $2002^{6}$ observándose la permanencia de esta forma de destierro y desarraigo que es resultado de graves violaciones a los derechos humanos y el derecho internacional humanitario. Según los sistemas de información alrededor de 380.863 personas (CODHES) y 301.187 (Acción social) en 2008 fueron obligadas a dejar su lugar de vivienda o trabajo para sumarse a este delito de lesa humanidad.

Gráfico 2. Número de personas desplazadas comparación Acción social-CODHES

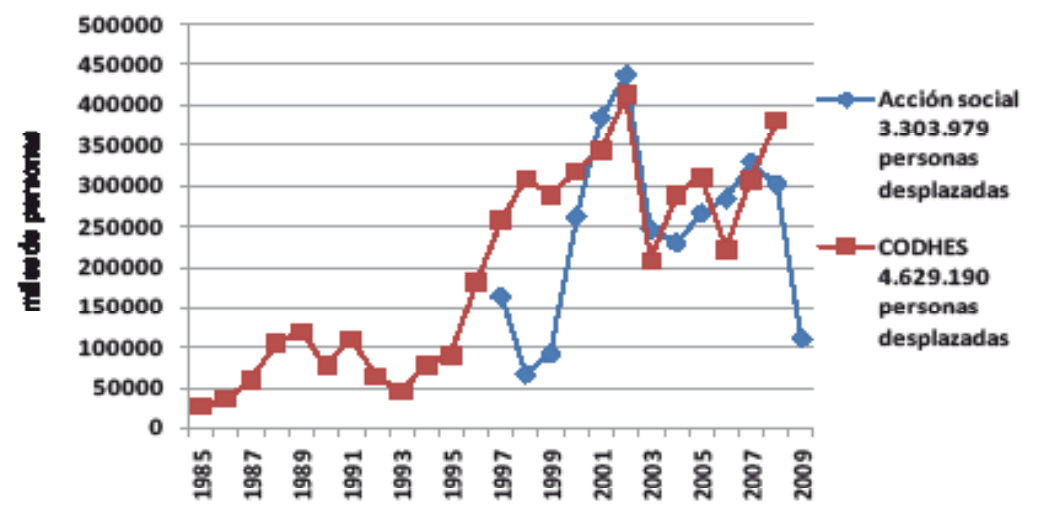

Fuente: Elaboración Propia con base a datos Acción Social Colombia y CODHES.

Desde 2006 el desplazamiento forzado registra una tendencia creciente que refleja la consolidación de hegemonías armadas ilegales tras cruentas luchas en las cuales la población campesina se convirtió en objetivo militar y sus tierras y bienes en trofeos de guerra. Es decir, en los últimos cuatro años más de un millón de personas han sido desplazadas si se tiene en cuenta que en 2006 el desplazamiento afectó a 221.638 personas, en 2007 a 305.966 personas, en 2008 a 380.863 personas y en 2009 a 111.000 personas (en cifras oficiales).

Resulta sorprendente observar cómo la cifra de 2008 y, tal vez, la no oficial de 2009 son prácticamente iguales a las de 2002 año en que se produjo el desplazamiento forzado de 412.553 personas, periodo en que se produjo el rompimiento de los diálogos de paz en el Caguán entre el gobierno nacional y las fuerzas armadas revolucionarias

6 Se toma mayor fiabilidad de las estadísticas de CODHES por ser no oficiales, las de Acción social (oficiales) pueden presentar sesgo político dado que el gobierno de turno busca una tercera reelección. 
FARC y el inicio de una fuerte confrontación armada.

El periodo comprendido entre 1985 y 2008 el desplazamiento forzado afectó a un total aproximado de 4.629 .190 personas que integran en promedio 925.828 familias según datos no oficiales (CODHES, 2009). Por su parte, el gobierno registra oficialmente en sus sistemas estadísticos 3.303.979 entre 1997 y 2009 cifra parcial que no incluye los datos anteriores al año 1997. El fenómeno como se ha denominado en este artículo y por otros expertos en el tema, podría catalogarse como un verdadero drama social y humanitario para Colombia.

Gráfico 3. Departamentos de mayor expulsión de personas Fuente: Elaboración Propia con base en datos Acción Social Colombia, CODHES, e IDMC.

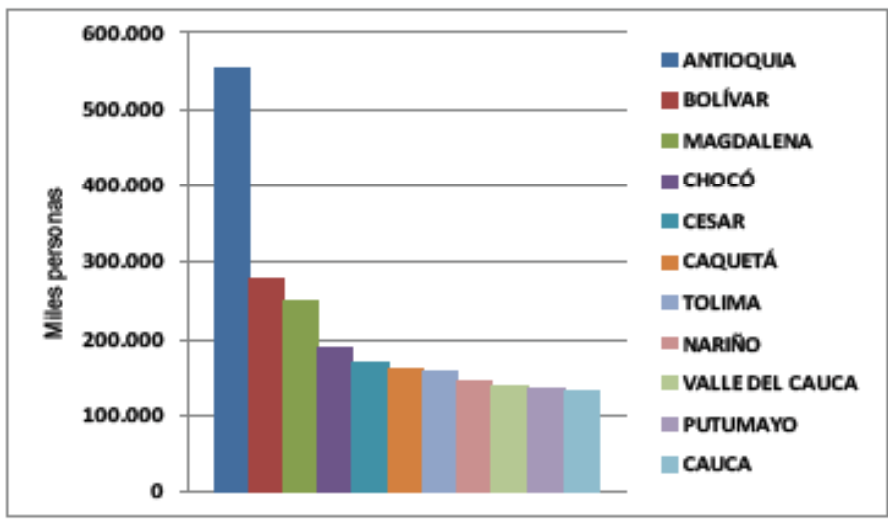

Cifras acumulativas de población por departamento desde antes de 1997 hasta 2010

Por otro lado, al analizar las dinámicas regionales de expulsión de personas y familias se puede evidenciar que existe un mayor impacto en las regiones que presentan serios problemas estructurales. Tomado como referencia el número de personas expulsadas en las estadísticas los departamentos más afectados fueron en su orden Antioquia, Bolívar, Magdalena, Chocó, Cesar, Caquetá, Tolima, Nariño, Valle del Cauca, Putumayo y Cauca. Departamentos que registran un acumulado de personas desplazadas expulsadas superior a las 130.000 personas. Ver Gráfico 3 y Mapa 1.

Al respecto la comisión de seguimiento afirmó que desde el año 2000385.000 familias rurales abandonaron 5.5 millones de hectáreas, equivalentes al $10.8 \%$ del área agropecuaria del país que generó un lucro cesante que ascendería a 49.7 billones, es decir, 11.7\% del PIB del país (Garay, 2009) y referencia las regiones arriba mencionadas. 
Mapa.1 Departamentos generadores de expulsión y recepción de personas

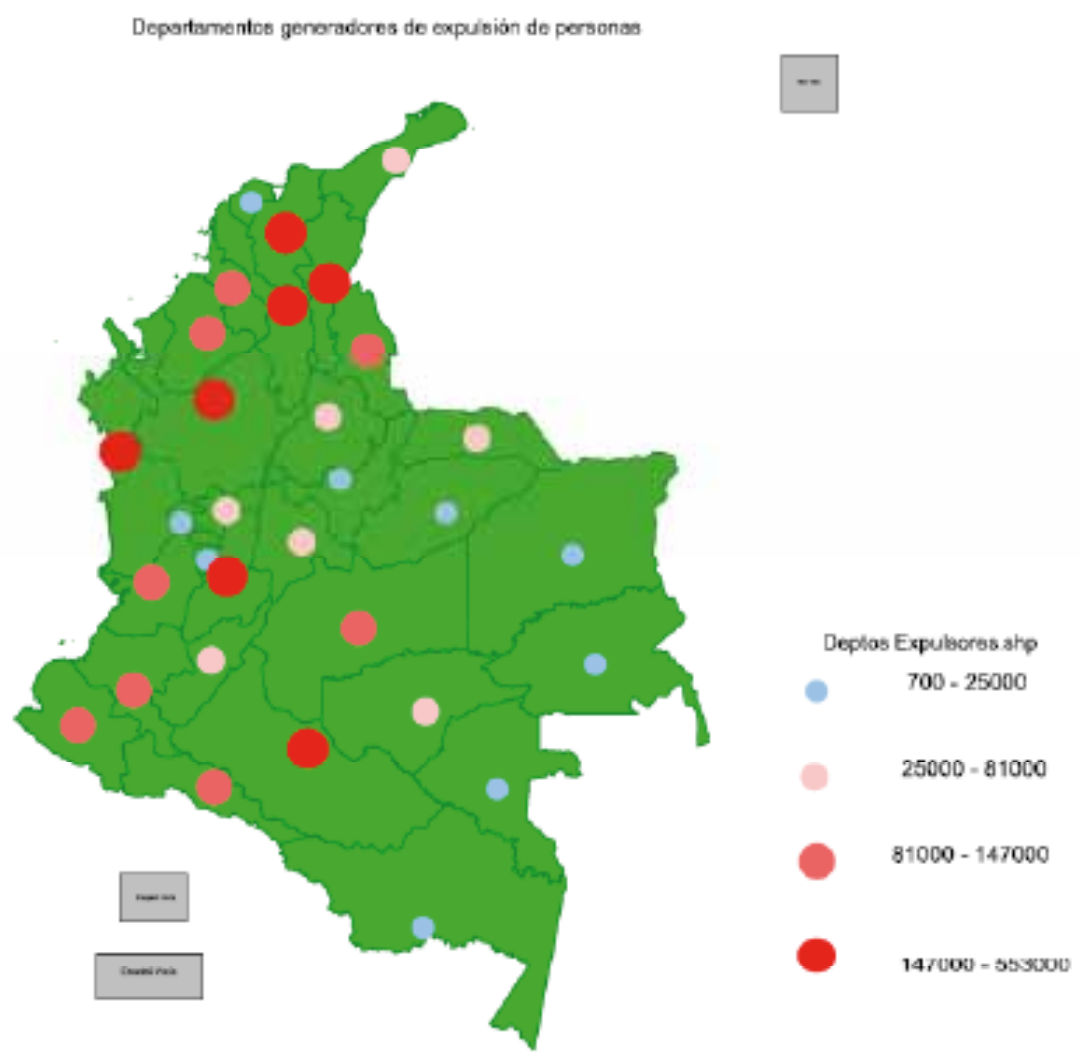

Fuente: Elaboración Propia con base en datos Acción Social Colombia, CODHES

Igualmente, dentro de esta dinámica se puede observar que existen unas regiones de acogida de este tipo de población las cuales soportan un flujo de personas con serias necesidades en materia de servicios sociales, de educación, salud, atención humanitaria y estabilización socioeconómica. Se puede percibir que extrañamente muchos de los mismos departamentos expulsores son también receptores esto obedece a que los desplazamientos ocurren en la mayoría de los casos de las zonas rurales del departamento a su capital por la cercanía cultural, lazos familiares, y amigos que facilitan la difícil situación en la que se encuentran. 
Gráfico 4. Departamentos de mayor recepción personas
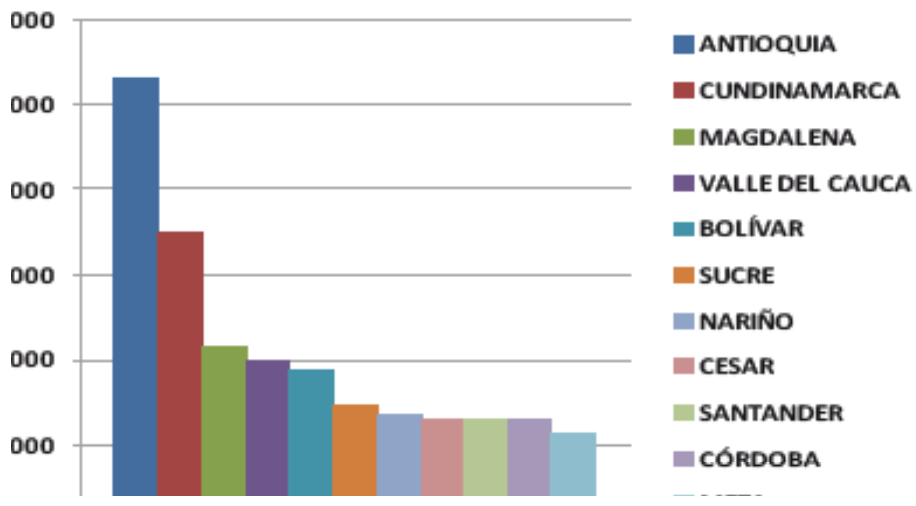

Fuente: Elaboración Propia con base en datos Acción Social Colombia, CODHES, e IDMC.

Cifras acumulativas de población por departamento desde antes de 1997 hasta 2010

Los departamentos de mayor recepción son en su orden Antioquia, Cundinamarca, Magdalena, Valle del Cauca, Bolívar, Sucre, Nariño y Cesar los cuales presentan una recepción de desplazados superior a las 130.000 personas como se puede apreciar en el Gráfico 4 y el Mapa 1. Pero es especialmente relevante señalar que son cinco departamentos los que concentran el $50 \%$ de expulsión y recepción de población desplazada Antioquia, Bolívar, Magdalena, Cesar y Valle del Cauca; y dentro de este subgrupo más focalizado llaman la atención Antioquia, Bolívar y Magdalena los cuales generaron cifras de expulsión y, a la vez, recepción por encima de las 200.000 personas.

Gráfico 5. Actores bélicos generadores de desplazamiento

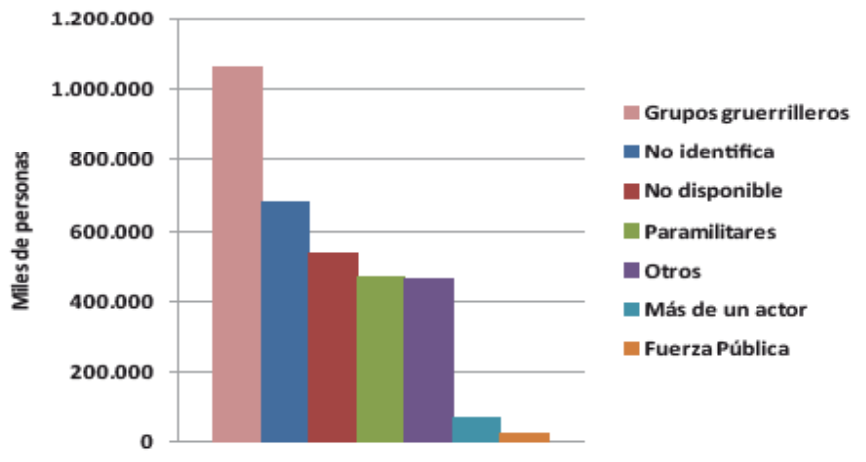

Fuente: Elaboración Propia con base en datos Acción Social Colombia, CODHES 
Por otro lado, al observar el tipo de actores que han generado los desplazamientos masivos, se encontró en las encuestas realizadas a las víctimas por Acción Social, las ONG y otras Organizaciones que los mayores perpetradores, causantes y generadores de daños colaterales a la población civil son los grupos guerrilleros, así mismo un alto porcentaje manifestó no identificar o conocer a los grupos o individuos generadores de la intimidación y, en tercer lugar, se observa que los grupos paramilitares y las fuerzas militares del Estado constituyen las fuerzas que han coaccionado y obligado a la población a salir de sus lugares habituales. Ver Gráfico 5. Esta circunstancia se constata al observar el tipo de actor generador por regiones ver Mapas 2 y 3.

Mapa $2 \quad$ Mapa 3

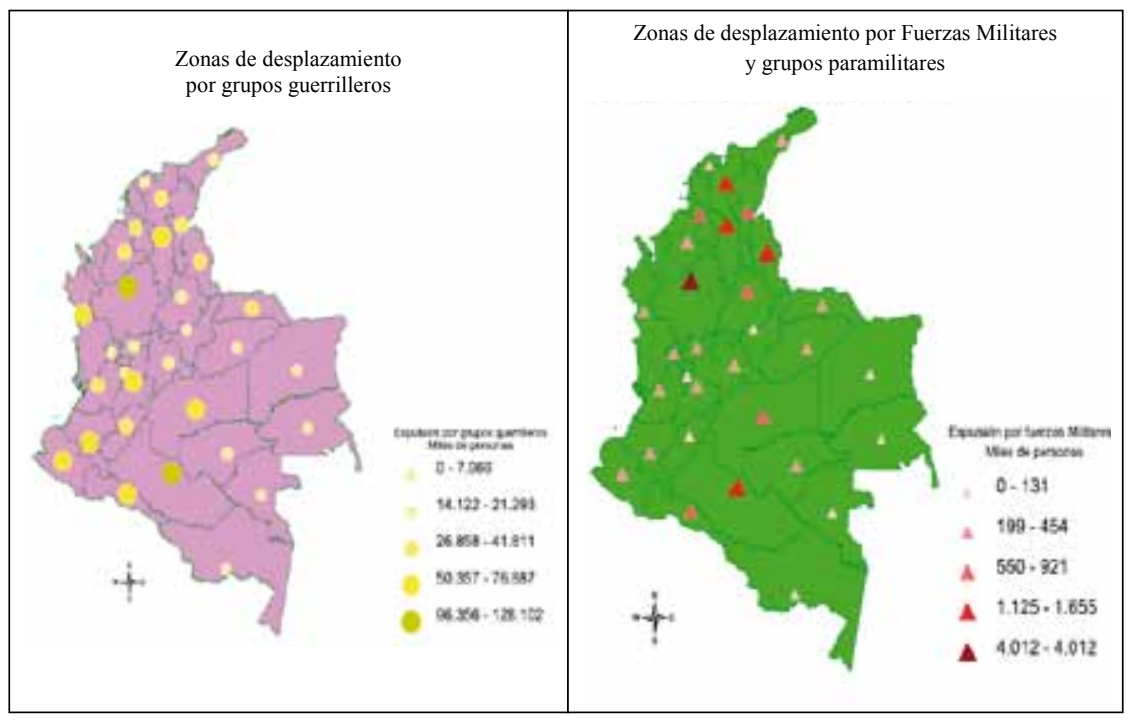

Fuente: Elaboración Propia con base en datos Acción Social Colombia. Expulsión total histórica acumulada en miles de personas según actor armado hasta 2010 por regiones.

Se encontró igualmente datos cualitativos que permiten mostrar la relación existente entre el contexto y la dinámica del desplazamiento, dado que elementos como cultivos ilícitos, armas, drogas, disputas territoriales y exclusión social generan condiciones tan adversas que los individuos a pesar de no poseer nada más que su tierra prefieren abandonarla que perder la vida o la de sus familiares. Por tanto, al observar la geografía colombiana con este tipo de disputas se evidencia perfectamente relacionados los departamentos con problemas de armas, drogas, disputas territoriales y exclusión con los de mayor volumen de desplazamiento y, por tanto, se pone en absoluta evidencia las hipótesis de Mondragón, Fajardo, Cubidez y Domínguez sobre la existencia de factores estructurales (tierra, narcotráfico, 
disputas territoriales y exclusión social) asociados a las regiones expulsoras de la población desplazada. Por tanto, los cinco departamentos que concentran el $50 \%$ de expulsión y recepción de población desplazada Antioquia, Bolívar, Magdalena, Cesar y Valle del Cauca; constituyen las regiones con los problemas estructurales y sociales más graves. Ver Mapa 4.

Mapa 4 Zonas con problemas estructurales y sociales (Conflictos de tierras, narcotráfico, armas y exclusión social)

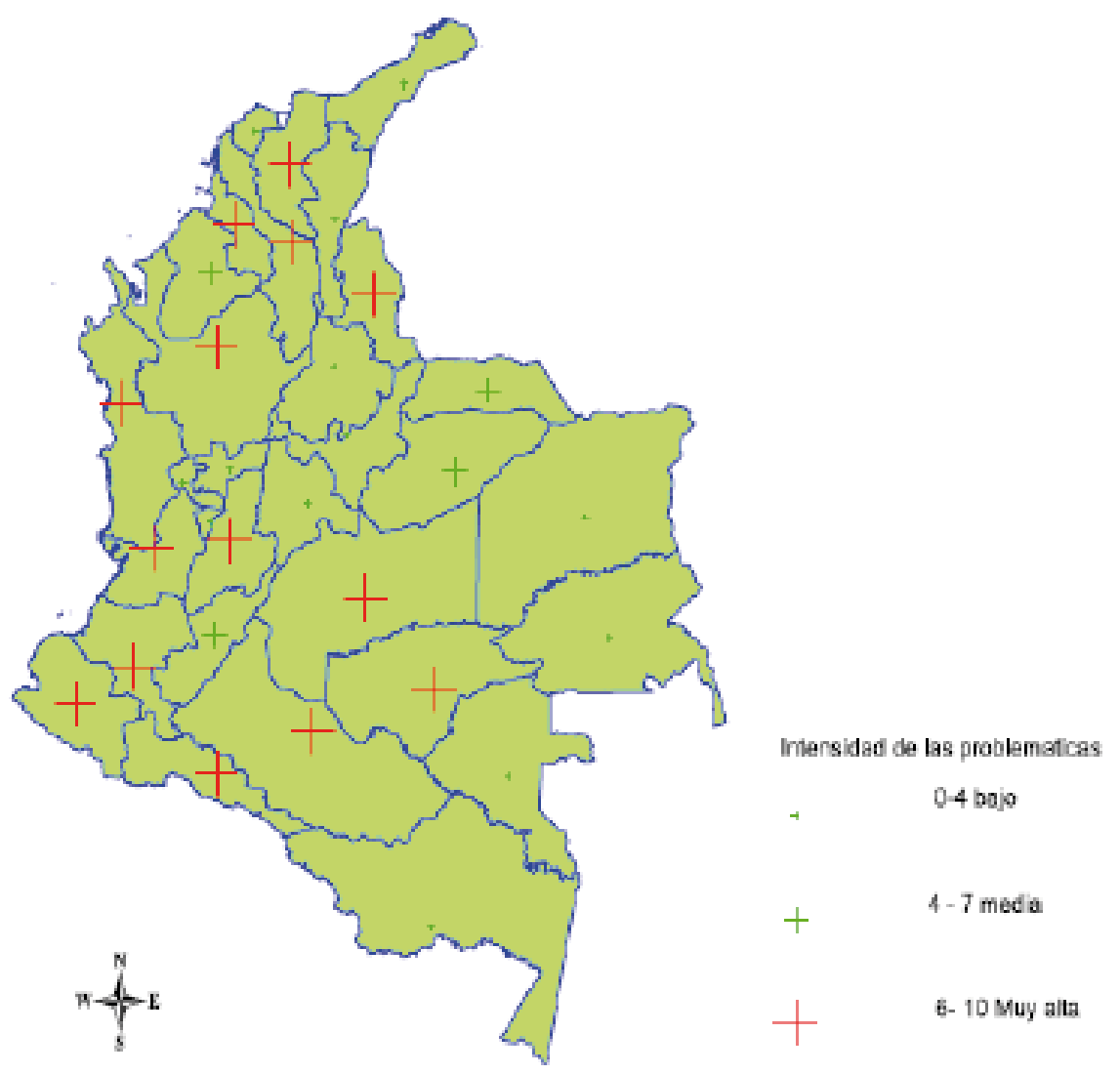

Fuente: Elaboración Propia con base en datos Acción Social Colombia 


\subsection{Perfil sociodemográfico de los desplazados}

La población desplazada presenta un perfil sociodemográfico bastante heterogéneo y diverso, diferenciado por etnias, razas, género y discapacitados entre otras clasificaciones, sin embargo, la ejecución de política pública incluye parcialmente el concepto de enfoque diferencial de atención y diseño de política, dado que se brinda atención en las mismas condiciones a comunidades étnicas, mujeres, indígenas, discapacitados y demás (Bello, 2009).

En este sentido se encontró que del total de la población desplazada el $56 \%$ de la población son mujeres y el $44 \%$ son hombres, así mismo al incluir a sus hijos se encontró que el $70 \%$ son mujeres con hijos y tan sólo el $30 \%$ son hombres. Al respecto la encuesta de población revela que del total de población desplazada, son las mujeres las que más resultan afectadas. Ver Gráfico 6

Gráfico 6. Participación de personas desplazadas por género
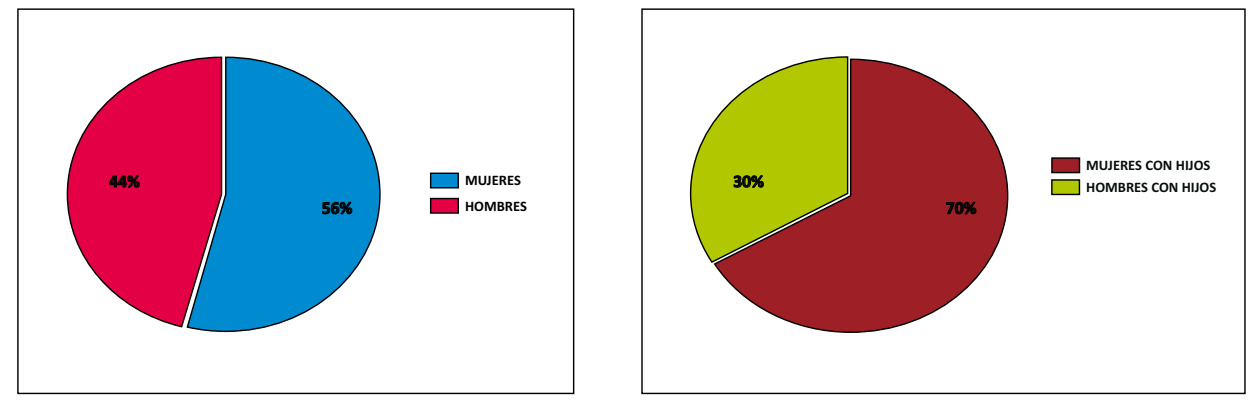

Fuente: Elaboración Propia con base en datos Acción Social Colombia. Cálculo realizado a partir de cifras históricas acumulativas de población por departamento desde antes de 1997 hasta 2010.

Con respecto a las edades de la población se encontró en las bases de datos que la mayor parte de la población se encuentra en el rango más productivo de su vida, o expresado en términos económicos más del $70 \%$ de la población desplazada es población económicamente activa y absolutamente joven. El rango de edad promedio oscila entre los 10 a los 35 años. Ver Gráfico 7. Según CODHES la mayor parte de esta población joven presenta un bajo nivel de escolaridad, de preparación técnica y de capacidad para insertarse al mercado laboral urbano, dado que las capacidades iníciales que poseen son de carácter agrícola. 
Gráfico 7. Rango de edad de personas desplazadas

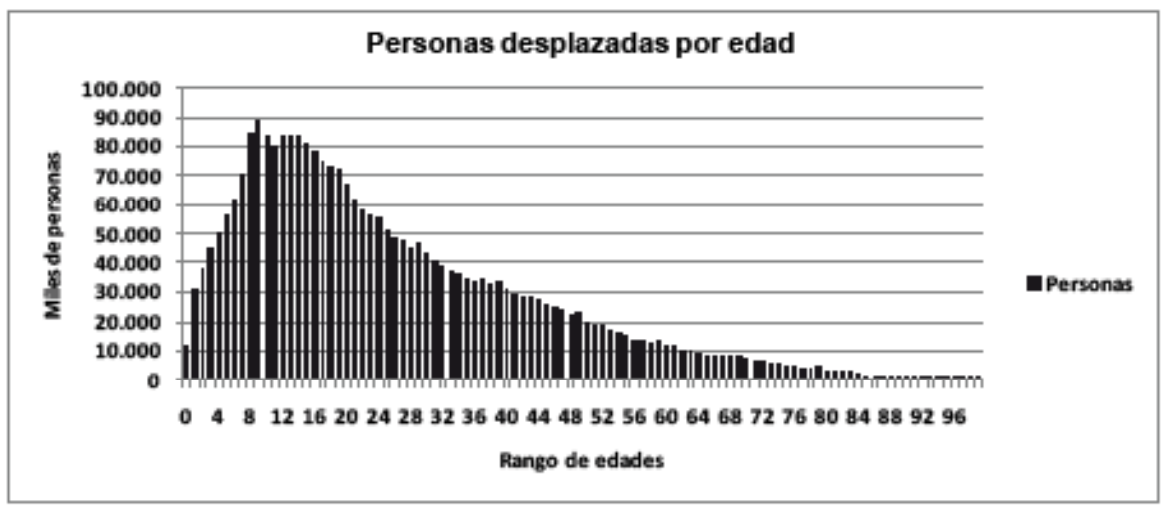

Promedio de edad del total de la población acumulado hasta 2010. Fuente: Elaboración Propia con base en datos Acción Social Colombia

Por otro lado, en términos de discapacidad al revisar las diversas fuentes estadísticas oficiales y no oficiales, se evidencia que aproximadamente el $1 \%$ del total de la población desplazada presenta problemas de discapacidad. Se observó que dentro de la población existen particularidades como ceguera, mudez, parálisis inferior, parálisis superior, retraso mental y sordera entre otras, ver Tabla 1. Al respecto la política social de asistencia y atención es precaria en términos de enfoque con discapacidad y atención especial.

Tabla. 1 Total histórico de discapacitados de la población total de desplazados

\begin{tabular}{|l|r|r|}
\hline \multicolumn{3}{|c|}{ TIPOS DE DISCAPACIDADES } \\
\hline \multicolumn{1}{|c|}{ DISCAPACIDAD } & \# DE PERSONAS & \% \\
\hline Ceguera & 2.566 & 0,1 \\
\hline Más de una incapacidad & 1.936 & 0,1 \\
\hline Mudez & 559 & 0,0 \\
\hline Otra & 18.870 & 0,6 \\
\hline Parálisis inferior & 2.237 & 0,1 \\
\hline Parálisis superior & 1.390 & 0,0 \\
\hline Retraso mental & 3.970 & 0,1 \\
\hline Sordera & 1.727 & 0,1 \\
\hline Total discapacitados & 33.255 & 1,0 \\
\hline Población desplazada & 3.303 .907 & 100 \\
Total histórico & &
\end{tabular}

Fuente: Elaboración Propia con base en datos Acción Social Colombia y CODHES 
El factor étnico es otro aspecto relevante en materia de estadística sociodemográfica, sin embargo, en términos de política no tanto, se observó que la atención suministrada por las agencias del Estado a las minorías étnicas no minimiza los daños causados y tampoco genera condiciones que propicien la protección de la cultura ancestral y autóctona, se establece una atención en las mismas condiciones y bajo modelos y estilos de vida que coartan las particularidades da cada etnia o grupo afro descendiente o indígena (CODHES 2008).

La mayoría étnica más afectada son las comunidades afro-colombianas que con un $8.12 \%$ del total acumulado de la población desplazada del país; seguido de la indígena $2.33 \%$ y los gitanos con un $0.60 \%$. Algunos autores abogan por una política paralela a la general en materia de atención y estabilización para este grupo de comunidades las cuales están en peores condiciones y en muchos casos bajo elementos de discriminación (Ibáñez, 2004)

\section{Política pública en materia de atención de víctimas del desplazamiento forzado}

El agudo problema humanitario y de derechos humanos del fenómeno del desplazamiento en el país llevó a diversas organizaciones de la sociedad civil, asociaciones de desplazados, comunidad internacional y algunas ONG a generar una presión social y jurídica tan fuerte sobre las instituciones del Estado colombiano que el 22 de enero de 2004 la Corte Constitucional se pronunció a través de la sentencia T-025 refiriéndose al desplazamiento como un estado de cosas inconstitucional. Esta circunstancia generó un mecanismo jurídico vinculante concreto sobre los diversos actores estatales tanto a nivel nacional como regional para paliar y resolver el problema.

Los principales objetivos que la sentencia T-025 pretendió y buscó concretar son esencialmente siete: en primer lugar, mejorar el sistema de información y registro de la población, generar espacios de participación efectiva de las organizaciones de población desplazadas en el diseño de política pública, generar obligación de los entes territoriales en el destino de recursos suficientes para proteger los derechos de la población desplazada, adoptar programas precisos para superar las falencias de capacidad institucional, divulgar y hacer cumplir la carta de derechos básicos de la población desplazada y realizar esfuerzos presupuestales a nivel nacional y regional para superar el estado de cosas.

A partir de allí la política pública se redefine y fortalece en materia de justicia transicional y en materia de desplazamiento y atención. La política de justicia transicional se constituye esencialmente en la Ley 975 de 2005 y la sentencia C-370 de 2006. Por su parte, la política pública en materia de desplazamiento y atención se concreta en la ley 387 de 2007 y el decreto 250 de 2005. 
La política pública en materia de justicia transicional se ha centrado en hacer frente a los crímenes cometidos por los actores armados y, en particular, proteger los derechos de las víctimas de tales crímenes a través de la verdad, la justicia y la garantía de no repetición. Por su parte, la política pública de desplazamiento y atención (ley 387 de 2007) se enmarca dentro de cuatro ejes básicos de tratamiento a la población desplazada la prevención, la atención humanitaria de emergencia, la estabilización socioeconómica y el retorno de la población; y el decreto 250 en un plan de atención integral centrado en enfoques territorial, diferencial, humanitario, restitutivo y de derechos.

A partir de estas generalidades y revisar toda la literatura crítica respecto al tema, puntos de vista de expertos y argumentaciones de diversas organizaciones sociales se evidencia que la política pública en materia de atención y cumplimiento de derechos no presenta avances significativos de superación de la crisis, por el contrario, parece estar condicionada a mantener el statu quo y en algunas circunstancias a empeorarlo. Ello ha llevado a numerosos analistas, investigadores y defensores de derechos humanos a replantear la situación y a afirmar que el Estado y la sociedad civil no han realizado una reparación integral e imparcial así como una estabilización socioeconómica a las víctimas de la violencia y el conflicto armado; por el contrario, se ha establecido una política de atención coyuntural y fragmentaria.

En este sentido, se puede evidenciar que existe una desarticulación en la aplicación de las políticas públicas gubernamentales tanto en la justicia transicional (Ley 975 de 2005 y sentencia C-370 de 2006) como en materia de desplazamiento (ley 387 de 2007 y decreto 250 de 2005) como lo expresan (Uprimny y Saffon, 2006)

“(...) la política pública en materia de justicia transicional invisibiliza la problemática del desplazamiento forzado, al tiempo que la política pública en materia de desplazamiento no tiene en cuenta las enseñanzas de las estrategias de justicia transicional ni de los derechos de la población desplazada como víctimas de conductas atroces (...) a pesar de que las políticas parecían tender a complementarse (...) lo que ha sucedido es lo contrario."

Respecto a la justicia transicional y a la efectividad de dicha política y, por ende, de la ley existen suficientes razones para cuestionar su eficacia y alcances. En primer lugar, desde su concepción los derechos que la ley promulga no son en definitiva derechos exclusivos en razón de la condición de víctimas del desplazamiento forzado sino por el contrario reiteraciones que los mismos tienen como ciudadanos colombianos lo que limita la profundidad y el alcance de la misma en términos de cambios estructurales del estado de cosas.

En ese sentido como lo estima (Garay 2009),

"La ley no reconoce a los desplazados ningún derecho propio de las víctimas de un crimen atroz, como lo son los derechos a la verdad, la justicia y la garantía de 
no repetición, ni remite otros instrumentos jurídicos que consagren esos derechos. Tampoco se refiere la ley a la relación que existe entre el desplazamiento forzado y el conflicto armado, y mucho menos a las implicaciones de qué relación tienen en términos de la identificación de los responsables del crimen, y de sus consecuentes obligaciones a ser sometidos a la justicia, a narrar la verdad sobre lo ocurrido, a reparar a sus víctimas y a no reincidir en el crimen."

Por tanto, al negarse la condición de víctimas de un crimen atroz producto del conflicto interno no se ha generado una articulación entre la justicia transicional y la política de desplazamiento forzado lo que limita, de esta forma, un mayor alcance en la solución de la crisis de la población desplazada. Es injusta como está concebida la reparación desde el momento mismo de la concepción y consolidación de la ley de justicia y paz o justicia transicional; y es imprescindible mencionarlo y al respecto existe suficiente literatura y tinta explayada por juristas y analistas internacionales. En este sentido que el victimario (guerrillero o paramilitar) haga parte del proceso de reparación de los daños que ha causado, con los bienes que él "desee entregar o arreglar" y encontrarse personalmente las víctimas y victimarios en el proceso de reparación después eventos como asesinatos de seres queridos, sumado a elementos degradantes como tortura y violación: ¿No es un elemento injusto y, sobre todo, perverso de por sí de la ley?

En este sentido como lo manifiestan (Uprimny y Saffon, 2006)
"Ninguno de los instrumentos jurídicos contenidos de la política pública colombiana en materia de justicia transicional se refieren al desplazamiento forzado como una forma especial de crimen (...) esta política pública sectorial invisibiliza la especificidad de la problemática del desplazamiento forzado en Colombia."

Respecto a la política pública de desplazamiento y atención (ley 387 de 2007 y decreto 250) todas las críticas encontradas señalan un carácter coyuntural y de poca profundidad en la solución de la problemática. En este sentido se evidencia que no existen mecanismos concretos de prevención del fenómeno a nivel municipal y regional, igualmente, se observa en los diferentes informes que la política de atención humanitaria de emergencia es concretamente transitoria y desajustada del tiempo real del desplazamiento limitándose su entrega a un máximo de 5 meses, por tanto, desalineada de las necesidades reales de la población.

Por su parte, la estabilización socioeconómica carece de un enfoque de largo plazo planificado y sostenible, dado que centra el esfuerzo y los recursos institucionales en mini proyectos productivos disgregados y con poco impacto para la superación de bajos ingresos de las poblaciones. La política de retorno a los lugares de origen de la población no posee una planeación estructurada y sostenible y, mucho menos, con garantías reales de seguridad. (Garay 2009, CODHES 2010, PDPMM 2009). 
Por tanto, en términos generales debe hacérsele a la política pública en relación a la justicia transicional así como a la relativa en materia de desplazamiento forzado, una redefinición concreta que permita generar mecanismos reales verdad, justicia, reparación integral y garantía de no repetición; así como la solución de problemas de fondo relativos a la estabilización socioeconómica, la protección de bienes, y el acceso efectivo al goce de derechos; igualmente esfuerzos en la implementación práctica de tratamiento especial a poblaciones desplazadas con mayor vulnerabilidad (niños, mujeres y minorías étnicas e indígenas) tratamiento que implica la utilización de instrumentos diferenciales reales de operación institucional.

\section{Conclusiones}

La contribución de esta investigación consiste en presentar y reafirmar algunos hallazgos de la problemática del desplazamiento forzado interno en Colombia, en primer lugar sostener que existen antecedentes histórico-estructurales que condicionaron las raíces centrales del problema, es evidente que la violencia e insurgencia crónica se constituyen en una de las causas principales del desplazamiento, consolidándose como parte de una estrategia de los actores armados en la expansión y dominio territorial.

El fenómeno del desplazamiento está asociado a serios problemas históricoestructurales: la violencia, el problema de distribución de la tierra, el narcotráfico como combustible de los grupos armados y dinamizador de la violencia y la exclusión social por parte del Estado, los cuales al no haberse solucionado a través del tiempo se han traducido en un deterioro consecutivo de la violencia.

Al observar las dinámicas regionales se evidencia que existe una tendencia creciente del problema de desplazamiento durante la última década y que persistirá aún en el tiempo. Dentro de esta dinámica se puede observar que existen unas regiones de acogida las cuales soportan un flujo de personas con serias necesidades en materia de servicios sociales, de educación, salud, atención humanitaria y estabilización socioeconómica. Se puede percibir que extrañamente muchos de los mismos departamentos expulsores son también receptores esto obedece a que los desplazamientos ocurren en la mayoría de los casos de las zonas rurales del departamento a su capital por la cercanía cultural, lazos familiares y amigos que facilitan la difícil situación en la que se encuentran.

Señalar que son cinco departamentos los que concentran el 50\% de expulsión y recepción de población desplazada Antioquia, Bolívar, Magdalena, Cesar y Valle del Cauca; y dentro de este subgrupo la atención más focalizada la llaman Antioquia, Bolívar y Magdalena los cuales generaron cifras de expulsión y, a la vez, recepción por encima de las 200.000 personas. Por tanto, el Estado debe implementar una política focalizada en todos los campos sociales y estructurales en estas regiones más afectadas para frenar y solucionar el problema de fondo. 
Se evidenció así mismo que la población femenina es la más afectada (56\%) por el fenómeno del desplazamiento especialmente las mujeres cabeza de hogar y con hijos, por tanto, se hace necesario una política diferencial en materia de género. Igualmente se observa que la mayor parte de la población, el $70 \%$, es población muy joven entre los 10 y 33 años y presenta un bajo nivel de escolaridad, de preparación técnica y de capacidad para insertarse al mercado laboral urbano, dado que las capacidades iníciales que poseen son más de carácter agrícola

El factor étnico es otro aspecto relevante en materia de estadística sociodemográfica, sin embargo, en términos de política no tanto, se observó que la atención suministrada por las agencias del Estado a las minorías étnicas no minimiza los daños causados y tampoco genera condiciones que propicien la protección de la cultura ancestral y autóctona, se establece una atención en las mismas condiciones y bajo modelos y estilos de vida que coartan las particularidades da cada etnia o grupo afro descendiente o indígena. La mayoría étnica más afectada son las comunidades afro colombianas con un $8.12 \%$ del total de la población desplazada del país; seguido de la indígena $2.33 \%$ y los gitanos con un $0.60 \%$. Algunos autores abogan por una política paralela a la general en materia de atención y estabilización para este grupo de comunidades las cuales están en peores condiciones y, en muchos casos, bajo elementos de discriminación.

La política pública presenta serios problemas de formulación y ejecución tanto en materia de justicia transicional como en materia de desplazamiento y atención. Sin lugar a dudas, prevalece una precariedad en su concepción y ejecución así como en la capacidad de articulación que posibilite una reparación integral de las víctimas, la garantía de sus derechos, la no repetición, la estabilización socioeconómica y el retorno.

Por consiguiente, es vital para avanzar en la superación del estado de crisis, en primera instancia, una redefinición de las leyes y políticas así como una articulación de las políticas públicas en materia de justicia transicional y de desplazamiento forzado que defina los derechos consagrados en una y otra política en una dimensión integral

Por último, es necesario mencionar que dentro de una verdadera reparación integral a las víctimas de la violencia y conflicto armado en Colombia, se requiere una verdadera articulación entre los cinco actores involucrados: el Estado, las guerrillas insurgentes, los paramilitares, la comunidad internacional y, sobre todo, la sociedad civil. ¿Por qué la comunidad internacional? Porque el conflicto armado interno obedece en gran medida a un proceso de configuración mundial de la economía (el mercado mundial de narcotráfico, los capitales internacionales, multinacionales) y el modelo de desarrollo económico -neoliberal- que configura la estructura social donde se desempeñarán los diferentes actores y sociedad civil en el futuro próximo. 


\section{Referencias Bibliográficas}

ACOSTA, J. (2005): La internacionalización de los derechos humanos y los mecanismos de protección de los refugiados. Universidad Girona.

Agencia Presidencial para la Acción Social y la Cooperación Internacional de Colombia (Acción Social). Estadísticas de la población desplazada (2009). Disponible en página Web: http://www.accionsocial.gov.co/Estadisticas/ publicación /diciembre/de2009.htm

BANCO DE DATOS DE DERECHOS HUMANOS Y VIOLENCIA POLÍTICA. (2010) Marco conceptual.

BELLO, M. (2004) El desplazamiento forzado en Colombia: acumulación de capital y exclusión. En: Desplazamiento forzado: Dinámicas de guerra, exclusión y desarraigo. ACNUR, Universidad Nacional de Colombia.

CAMPS, N. (2005): El derecho internacional ante las migraciones forzadas. Ediciones Universidad Lleida. Lleida

CODHES (2006) CONFERENCIA EPISCOPAL DE COLOMBIA. Desafíos para construir nación. El país ante el desplazamiento, el conflicto armado y la crisis humanitaria.1995-2005. CODHES, Bogotá

CUBIDEZ, F; DOMÍNGUEZ C. (1999): Desplazados, migraciones internas y restructuraciones territoriales. CES.

GARAY L. (2009) Reparar de manera integral el despojo de tierras y bienes el reto ante la tragedia humanitaria del desplazamiento forzado.

IBÁÑEZ, A, M y QUERUBÍN, P (2004). Acceso a tierras y desplazamiento forzado en Colombia. Documento CEDE. Bogotá : Universidad de los Andes, CEDE; mayo 2004. p 10 21. Ibíd. p.10

Internal Displacement monitoring Center (2008). Global overview of trends and developments in 2008. Consultado en la página Web http://www.internaldisplacement.org

Ley 387 de 1997. Por la cual se adoptan medidas para la prevención del desplazamiento forzado; la atención, protección, consolidación y estabilización socioeconómica de los desplazados internos por la violencia en la República de Colombia. 
United Nations. (2004) Office for the Coordination of Humanitarian Affairs. Guiding Principles on Internal Displacement.

MONDRAGÓN, H. (1998). Relatifundización, megaproyectos y campesinos en Colombia. www.gratisweb.com/ciclocrisis/latifundio.htm

NACIONES UNIDAS, (1951a, 1967b): Convención sobre estatuto de los refugiados.

NARANJO, G. Scripta nova No 94, 1 de agosto de 2001. http://www.ub.es/geocrit/ sn-94-37.htm

ROJAS, C (2001). Civilización y violencia. Bogotá: Editorial Norma.

TOVAR, H (2001) . Emigración y éxodo en la historia de Colombia en Migrations en Colombie. Cahiers Alhim, No.3,- 2001. http://alhim.revues.org/document522. html

URIBE M, T (2000). Desplazamiento forzado en Antioquia. Vol. 0 Aproximaciones teóricas y metodológicas al desplazamiento de población en Colombia. 1a Ed. Bogotá Conferencia Episcopal de Colombia, p 44.

URIBE, M. Las soberanías en vilo en un contexto de guerra y paz. Estudios Políticos, W.P No 13, Medellín: 1998, p. 20.

ZULUAGA, J (2004). La guerra interna y el desplazamiento forzado. En: Desplazamiento forzado: Dinámicas de guerra, exclusión y desarraigo. ACNUR, Universidad Nacional de Colombia. 


\section{ANEXOS}

Anexo 1. Mapa departamental de Colombia

Fuente: Instituto geográfico de Colombia Agustín Codazzi www.igac.gov.co

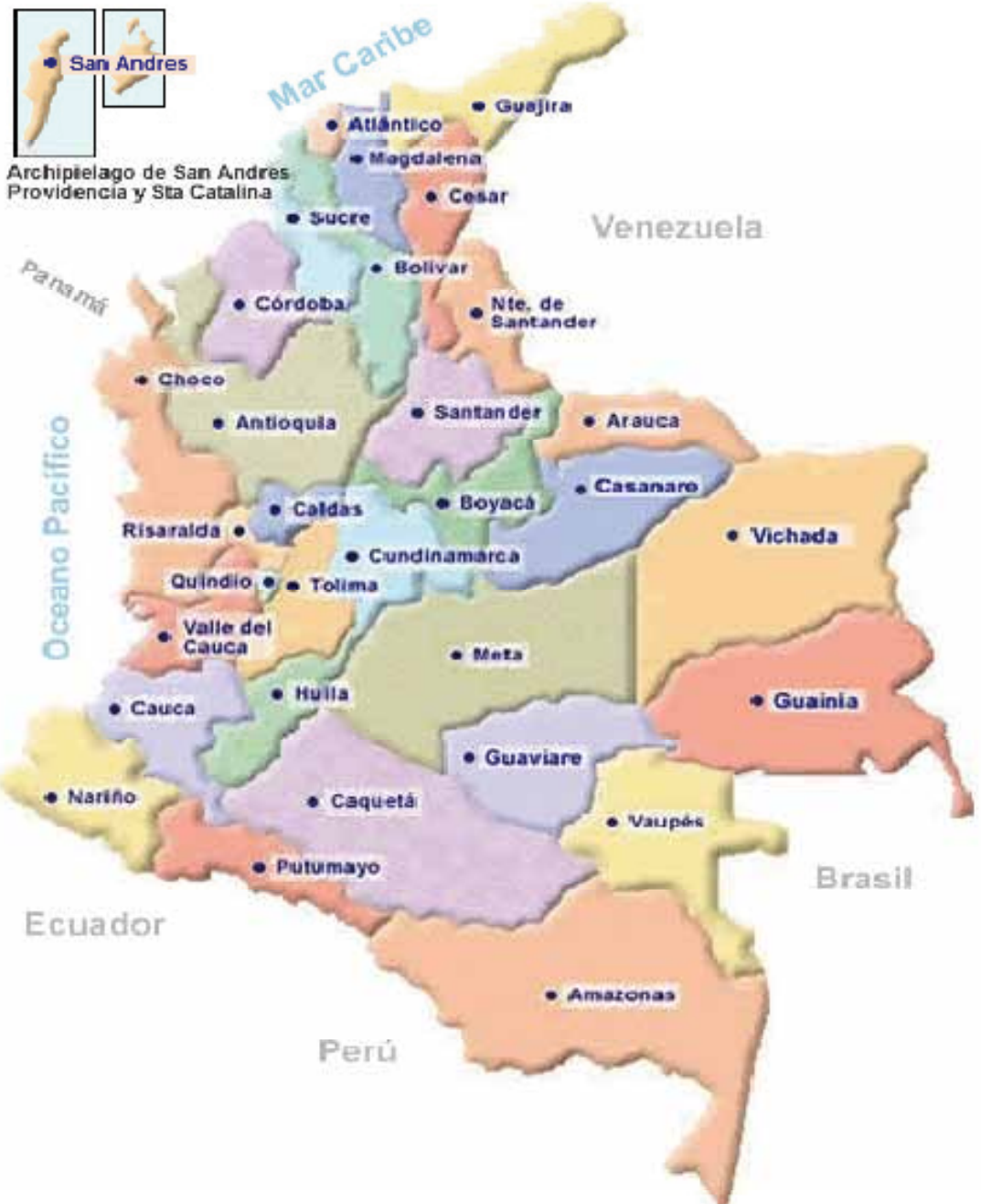


